\title{
Analiza widmowa wyższych rzędów akustycznych sygnałów procesu spawania
}

\author{
Higher order spectral analysis of acoustical signals of welding \\ process
}

Słowa kluczowe: MAG; monitorowanie spawania; analiza widmowa wyższych rzędów; sygnały akustyczne

\section{Streszczenie}

W artykule zaprezentowano wyniki badań nad zastosowaniem widma trzeciego rzędu do analizy sygnałów akustycznych generowanych $w$ trakcie spawania. Widma wyższych rzędów w przeciwieństwie do powszechnie stosowanego widma mocy sygnału zachowują informację o zależnościach fazowych i pozwalają w pełni scharakteryzować niestabilności procesu spawania, co potwierdzają przeprowadzone badania.
\end{abstract}

\section{Wstęp}

Od dłuższego czasu zarówno w kraju, jak i na świecie rozwijane są metody monitorowania i oceny stabilności procesu spawania w trybie on-line. Zaowocowało to różnorodnymi rozwiązaniami układów monitorowania i diagnostyki wykorzystującymi zarówno klasyczne sygnały procesowe (np. prąd i napięcie), jak również wąsko i szerokopasmowe sygnały mocy promieniowana łuku spawalniczego, sygnały akustyczne i drganiowe, a także obrazy wizyjne i termowizyjne.

Wśród rozwijanych sposobów monitorowania procesu spawania na szczególną uwagę zasługują metody wykorzystujące sygnały akustyczne. Sygnały akustyczne są naturalnym źródłem informacji wykorzystywanym od lat przez wykwalifikowanych spawaczy przy spawaniu łukowym w celu kontroli poprawności wykonywanej przez nich spoiny. Zmiana geometrii elementów łączonych, zanieczyszczenia, chwilowe zmiany własności materiałowych, różnice w długości łuku, zmiana parametrów prądu i napięcia natychmiast znajdują odzwierciedlenie w sposobie jarzenia się łuku elektrycznego a zatem i również w sygnale akustycznym generowanym podczas spawania. Zalety wykorzystania sygnałów akustycznych do monitorowania stabilności procesu spawania potwierdzają liczne badania.

W [2] i [3] oceniano stabilność spawania na podstawie parametrów statystycznych przeprowadzając teoretyczną i eksperymentalną analizę możliwości zastosowania sygnałów akustycznych do monitorowania procesu spawania metodą GMA w warunkach przemysłowych. Wyniki badań przedstawione w [4] pokazują, że energia akustyczna jest proporcjonalna do ubytku materiału w chwili powstawania odprysków. Badania dotyczące analizy sygnałów dźwiękowych pozwoliły na wskazanie mechanizmów powstawania fal akustycznych [1] i wskazanie ścisłych związków z charakterystycznymi cechami sygnałów procesowych i jakością uzyskiwanych złączy spawanych [6]. Sygnały dźwiękowe i ich cechy stanowią również źródło danych dla sztucznych sieci neuronowych stosowanych w detekcji i identyfikacji nieprawidłowości procesu spawania [7].

Skuteczna detekcja i identyfikacja niezgodności procesu spawania wymaga odpowiedniego przetwarzania i analizy sygnałów procesowych. Istnieją różne metody pozwalające oceniać sygnały procesowe w tym sygnały akustyczne [5]. Wykorzystują one parametry statystyczne, różnorodne przekształcenia przestrzeni wartości sygnałów (np. Transformata Fouriera, PCA) itp. Należy jednak zauważyć, że analiza sygnałów spawania nie jest zadaniem prostym ze względu na ich dynamiczny i niestacjonarny charakter oraz duży udział składowych losowych.

W artykule przedstawiono przykład wykorzystania, znanych od dawna [8,9], ale bardzo rzadko stosowanych w analizie sygnałów spawania, statystyk i widm wyższych rzędów

Dr hab. inż. Marek Fidali, prof. PŚI - Politechnika Śląska.

Autor korespondencyjny/Corresponding author. marek.fidali@polsl.pl 
dla potrzeb detekcji niestabilności i identyfikacji niezgodności spawalniczych na podstawie sygnałów akustycznych procesu spawania.

\section{Analiza widmowa wyższych rzędów}

Analiza sygnałów generowanych podczas spawania oparta na funkcji korelacji, widmie mocy sygnału czy rozkładach czasowo-częstotliwościowych posiada pewne ograniczenia w zakresie możliwości badania i opisu związków fazowych zachodzących między składowymi sygnału $[8,9]$. Ograniczenia te można pominąć poprzez stosowanie analizy sygnałów bazującej na kumulantach wyższych rzędów i ich widmach.

Kumulanta n-tego rzędu jest definiowana jako różnica między n-tym momentem sygnału $x(t)$ i $n$-tym momentem równoważnego mu stacjonarnego sygnału o rozkładzie normalnym. W związku z tym kumulanta przyjmuje wartości zerowe dla sygnałów o rozkładzie normalnym. Dla sygnału stacjonarnego $\mathrm{x}(\mathrm{t})$ o wartościach rzeczywistych i zerowej wartości średniej $E\{x(t)\}=0$ kumulanty pierwszego, drugiego, trzeciego i czwartego rzędu zdefiniowane są następująco [9]:

$\mathrm{C}_{1 \mathrm{x}}=\mathrm{E}\{\mathrm{x}(\mathrm{t})\}=0$,

$\mathrm{C}_{2 x}(\mathrm{k})=\mathrm{E}\{\mathrm{x}(\mathrm{t}) \cdot \mathrm{x}(\mathrm{t}+\mathrm{k})\}$,

$\mathrm{C}_{3 \mathrm{x}}(\mathrm{k}, \mathrm{l})=\mathrm{E}\{\mathrm{x}(\mathrm{t}) \cdot \mathrm{x}(\mathrm{t}+\mathrm{k}) \cdot \mathrm{x}(\mathrm{t}+\mathrm{l})\}$,

$\mathrm{C}_{4 \mathrm{x}}(\mathrm{k}, \mathrm{l}, \mathrm{m})=\mathrm{E}\{\mathrm{x}(\mathrm{t}) \cdot \mathrm{x}(\mathrm{t}+\mathrm{k}) \cdot \mathrm{x}(\mathrm{t}+\mathrm{l}) \cdot \mathrm{x}(\mathrm{t}+\mathrm{m})\}-\mathrm{C}_{2 \mathrm{x}}(\mathrm{k}) \cdot \mathrm{C}_{2 \mathrm{x}}(\mathrm{l}-\mathrm{m})-$

$$
+\mathrm{C}_{2 \mathrm{x}}(\mathrm{l}) \cdot \mathrm{C}_{2 \mathrm{x}}(\mathrm{k}-\mathrm{m})-\mathrm{C}_{2 \mathrm{x}}(\mathrm{m}) \cdot \mathrm{C}_{2 \mathrm{x}}(\mathrm{k}-\mathrm{l}) \text {, }
$$

Kumulanta pierwszego rzędu jest równa wartości oczekiwanej sygnału, kumulanta drugiego rzędu to kowariancja. Dla zerowych przesunięć czasowych kumulanty stają się parametrami liczbowymi takimi jak: wariancja $C_{2 x}(0)=\sigma_{x}{ }^{2}$, asymetria $\mathrm{C}_{3 \mathrm{x}}(0,0) / \sigma_{\mathrm{x}}{ }^{3}$ i kurtoza $\mathrm{C}_{4 \mathrm{x}}(0,0,0) / \sigma_{\mathrm{x}}{ }^{4}$.

Zastosowanie transformaty Fouriera wobec kumulant pozwala na wyznaczenie widm wyższych rzędów a mianowicie widma mocy sygnału $S_{2 x}(f)(5)$, bispektrum $S_{3 x}(6)$ i trispektrum $S_{4 x}\left(f_{1}, f_{2}, f_{3}\right)(7)$, w następujący sposób [9]:

$$
\begin{aligned}
& S_{2 x}(f)=\sum_{k=-\infty}^{\infty} \cdot C_{2 x}(k) \cdot e^{-j 2 \pi f k} \\
& S_{3 x}\left(f_{1}, f_{2}\right)=\sum_{k=-\infty}^{\infty} \cdot \sum_{l=-\infty}^{\infty} \cdot C_{3 x}(k, l) \cdot e^{-j 2 \pi f\left(f_{1} k+f_{2} l\right),} \\
& S_{4 x}\left(f_{1}, f_{2}, f_{3}\right)=\sum_{k=-\infty}^{\infty} \cdot \sum_{1=-\infty}^{\infty} \cdot \sum_{m=-\infty}^{\infty} \cdot C_{4 x}(k, l, m) \cdot e^{-j 2 \pi f\left(f_{1} k+f_{2} l+f_{3} m\right),}
\end{aligned}
$$

Analiza sygnałów z wykorzystaniem kumulant wyższych rzędów i ich widm umożliwia badanie statystycznych zależności pomiędzy składowymi częstotliwościowymi sygnału, wykrywanie i identyfikację składowych powstałych w wyniku występowania zjawisk nieliniowych oraz dodatkowych sprzężeń zwrotnych, a także redukcję szumów w sygnałach.

Metody te są szczególnie skuteczne tam, gdzie mamy do czynienia z procesami losowymi nie posiadającymi rozkładu normalnego.

W trakcie badań ograniczono się do stosowania analizy widmowej trzeciego rzędu w oparciu o bispektrum. Bispektrum jest ilościową miarą sprzężenia pomiędzy składowymi częstotliwościowymi, wyznaczoną na płaszczyźnie o odpowiednich współrzędnych częstotliwościowych nazywanych biczęstotliwościami [9]. Duża wartość bispektrum dla określonych par częstotliwości (i kombinacji ich sum lub różnic) wskazuje na istnienie sprzężenia częstotliwościowego pomiędzy nimi. Może to oznaczać, że rozważane składowe częstotliwościowe mają wspólny generator, co w obecności nieliniowości wyższych rzędów układu może prowadzić do syntetyzowania wspólnych nowych składowych częstotliwościowych. Jednym z powodów wystąpienia zjawisk nieliniowych jest kwadratowe sprzężenie fazy (Quadratic Phase Coupling). Bispektrum dodatkowo opisuje skośność funkcji gęstości rozkładu prawdopodobieństwa [8,9].
Bispektrum podobnie jak widmo mocy sygnału ma własności symetrii na płaszczyźnie $\left(\mathrm{f}_{1}, \mathrm{f}_{2}\right)$, co pozwala na ograniczenie obliczeń i prezentację wartości w obszarze nieredundantnym w postaci wykresów trójwymiarowych lub map. Ze względu na własności symetrii można wskazać obszar nieredundantny nazywany dziedziną główną (rys. 1) zdefiniowany przez trójkąt o wierzchołkach $(0,0),\left(\mathrm{f}_{\mathrm{s}} / 3, \mathrm{f}_{\mathrm{s}} / 3\right)$ $i\left(f_{s} / 2,0\right)$, gdzie $f_{s}$ jest częstotliwością próbkowania [9].

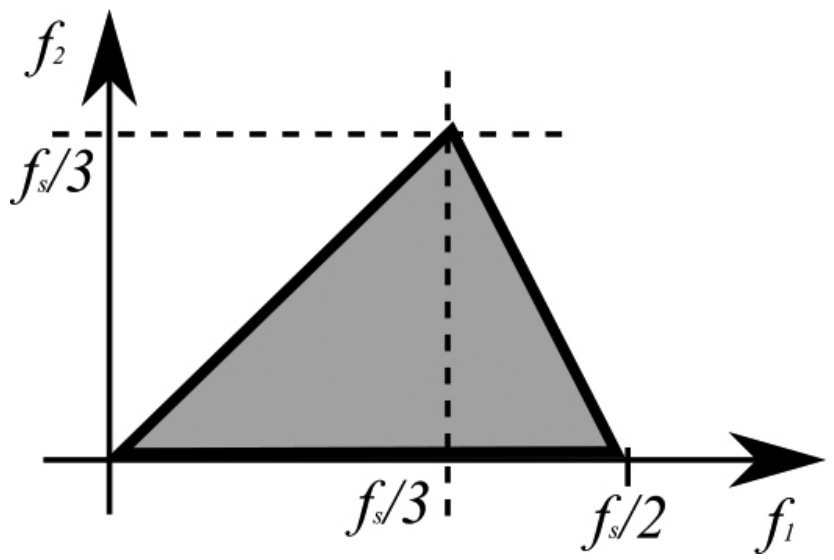

Rys. 1. Nieredundantny obszar wartości bispektrum przedstawiający dziedzinę główną

Fig. 1. The non-redundant part of the bispectral plane, showing the principal domain

W przypadku analizy sygnału akustycznego generowanego podczas procesu spawania, ze względu na jego niestacjonarny charakter sygnału celowa jest segmentacja realizacji sygnału na, krótsze podrealizacje, z których wyznaczane mogą być widma wyższych rzędów. Ponieważ wartości widm wyższych rzędów są zdefiniowane przez wielowymiarowe macierze wartości, konieczne jest określenie parametru liczbowego, opisującego całkowitą moc sygnału w dziedzinie głównej. Dla potrzeb niniejszych badań zdefiniowano parametr będący wartością maksymalną wartości widma wyższego rzędu wzdłuż głównej przekątnej stanowiącej granicę obszaru redundantnego (8):

$\mathrm{Sd}=\max \left(\operatorname{diag}\left(\left|\mathrm{S}_{3 \mathrm{x}}\left(\mathrm{f}_{1}, \mathrm{f}_{2}\right)\right|\right)\right)$

W przypadku, gdy sygnał będzie sygnałem losowym o rozkładzie Gaussa należy się spodziewać, że wartości parametru będą niskie. W przypadku silnych nieliniowości w bispektrum pojawią się intensywne składowe, co wpłynie również na znaczący wzrost wartości parametru Sd.

\section{Analizowane sygnały}

Dla potrzeb analiz z zastosowaniem widm wyższych rzędów wykorzystano sygnały akustyczne zarejestrowane w trakcie spawania odpowiednio przygotowanych próbek wykonanych z prostokątnych blach ze stali S235JR (EN 10027-1) o rozmiarach $300 \times 150 \times 5$ mm. Do spawania wykorzystano zmechanizowane stanowisko do prostoliniowego spawania metodą MIG/MAG (rys. 2). Jako materiał dodatkowy stosowano drut elektrodowy lity o średnicy 1,2 mm. Osłonę gazową stanowiła mieszanka M21 (82\% $\left.\mathrm{Ar}+18 \% \mathrm{CO}_{2}\right)$. Nominalne parametry spawania zaprezentowano w tablicy I.

W trakcie spawania rejestrowano sygnały akustyczne, korzystając z szerokopasmowego toru mikrofonowego (rys. 3) składającego się z:

- Mikrofonu pola swobodnego 40BE (G.R.A.S. ) o czułości $3,72 \mathrm{mV} / \mathrm{Pa}$ i paśmie przenoszenia $4 \div 100 \mathrm{kHz}$, wraz z osłoną przeciwwietrzną. 


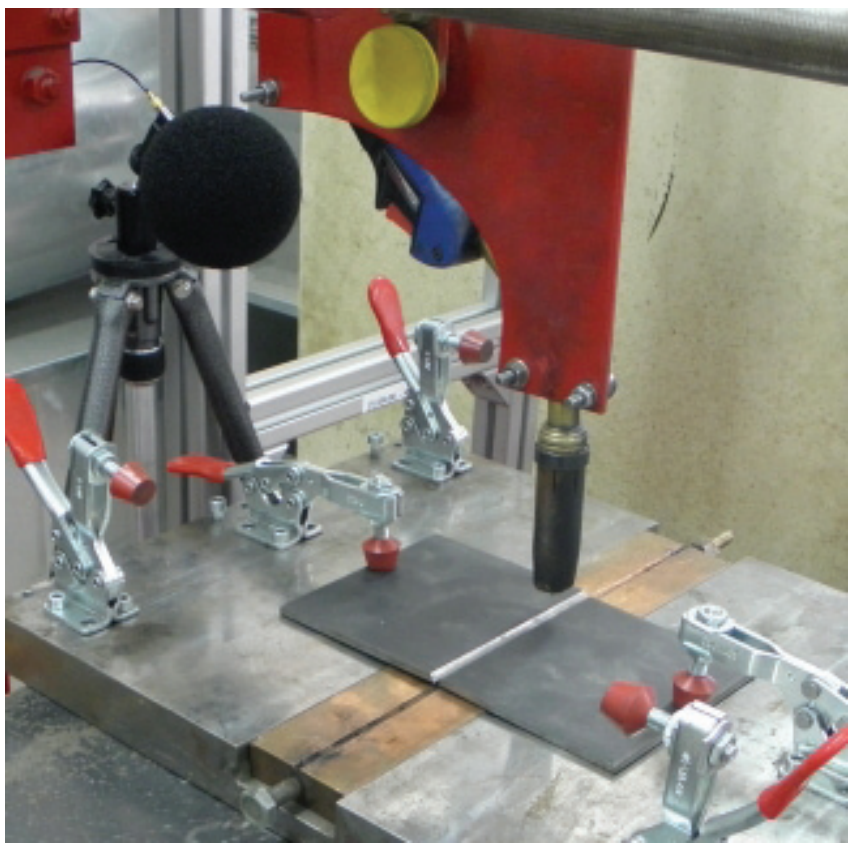

Rys. 2. Widok stanowiska badawczego

Fig. 2. View of the test bench

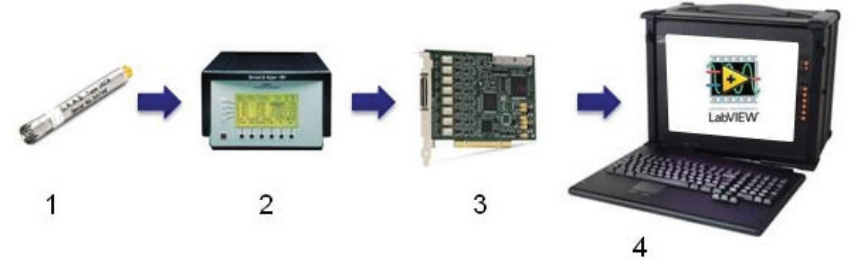

Rys. 3. Schemat toru pomiaru sygnału akustycznego: 1) Mikrofon z przedwzmacniaczem; 2) Wzmacniacz akustyczny; 3) Karta akwizycji sygnałów; 4) Komputer z oprogramowaniem

Fig. 3. Diagram of measurement setup of acoustical signals: 1) Microphone with preamplifier; 2) Acoustic amplifier; 3) ADC card; 4) PC with software

- Przedwzmacniacza 26CB (G.R.A.S.).

- Wzmacniacza mikrofonowego Nexus 2690A (Bruel\&Kjear).

- Komputera z wbudowaną 8-kanałowa, 16-bitową kartą akwizycji sygnałów PCl-6143 (National Instruments) o maksymalnej częstotliwości próbkowania $250 \mathrm{kS} / \mathrm{s}$ obsługiwaną przez oprogramowanie działające pod kontrolą programu LabView.

Synchroniczne wraz sygnałem dźwięku rejestrowano również takie parametry procesowe jak prąd, napięcie, prędkość spawania, przepływ gazu, prędkość podawania drutu.

$\mathrm{Na}$ stanowisku badawczym przeprowadzono szereg eksperymentów, w trakcie których symulowano różne nieprawidłowości procesu spawania wpływając tym samym na cechy jakościowe złącza spawanego. Symulowano m.in. takie stany procesu spawania jak:

S1 - spawanie bez zakłóceń;

S2- spawanie, podczas którego następowały zmiany wartości prądu;

S3- spawanie, w trakcie którego dokonywano zmian napięcia spawania;

S4- spawanie w trakcie, którego nastąpił zanik przepływu gazu osłonowego;

S5- spawanie blach z zabrudzeniami olejowymi na łączonych powierzchniach.

Eksperymenty przeprowadzono w ramach projektu badawczego nr N504 281937 pt. Metodologia diagnozowania procesu spawania z wykorzystaniem fuzji obrazów realizowanego w Instytucie Podstaw Konstrukcji Maszyn przy współpracy z pracownikami Katedry Spawalnictwa, Politechniki Śląskiej.
Tablica I. Nominalne parametry spawania łukowego metodą MAG Table I. Nominal parameters of GMA arc welding

\begin{tabular}{|l|c|}
\hline Prąd Spawania [A] & 240 \\
\hline Napięcie spawania [V] & 25 \\
\hline Prędkość spawania [cm/min] & 32 \\
\hline Prędkość podawania drutu [m/min] & 7,4 \\
\hline Natężenie przepływu gazu osłonowego [l/min] & 15 \\
\hline Wystający odcinek elektrody [mm] & 15 \\
\hline
\end{tabular}

\section{Wyniki badań}

Sygnały akustyczne zarejestrowane podczas spawania próbek testowych poddano przetwarzaniu polegającemu na wyznaczeniu bispektrów, które poddawano analizie. $\mathrm{Na}$ rysunku 4a przedstawiono przykładowe bispektrum wyznaczone dla sygnału akustycznego spawania zarejestrowanego w stanie S1. Zgodnie z własnościami bispektrum dostrzegalne są obszary symetrycznie rozłożone i redundantne. Wykres konturowy pierwszej ćwiartki wraz z zaznaczoną osią symetrii przedstawiono na rysunku 4b. Dla porównania rysunek 5 przedstawia bispektra wyznaczone kolejno dla stanów S2, S3, S4 i S5. Wyraźnie dostrzegalne są różnice w rozkładzie składowych częstotliwościowych, co potwierdziło tezę o możliwości wykorzystania bispektrum do oceny stabilności procesu spawania.
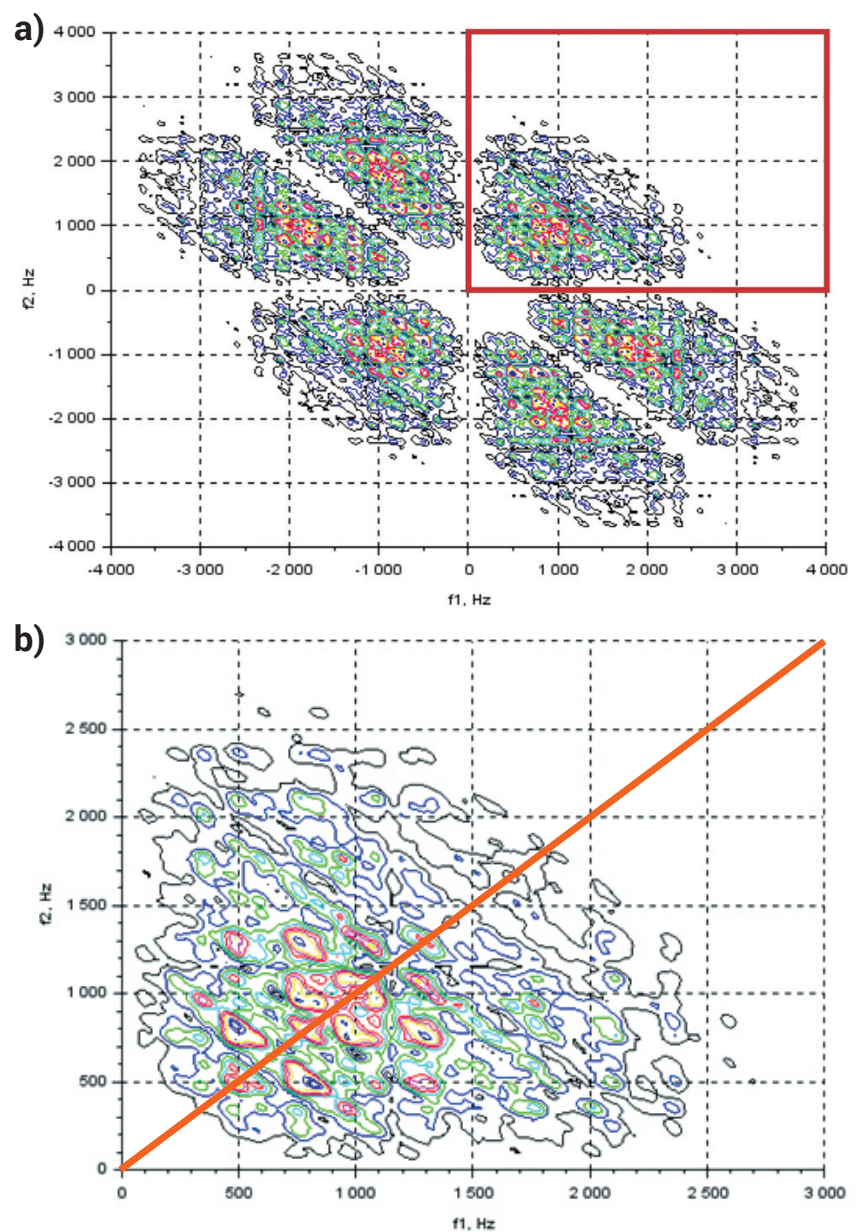

Rys. 4. Wykresy konturowe bispektrum dla sygnału akustycznego prawidłowego procesu spawania: a) pełne bispektrum; b) pierwsza ćwiartka bispektrum

Fig. 4. Contour plots of bispectra of acoustic signal for optimal weIding process: a) full bispectrum; b) first quarter of bispectrum 
a)

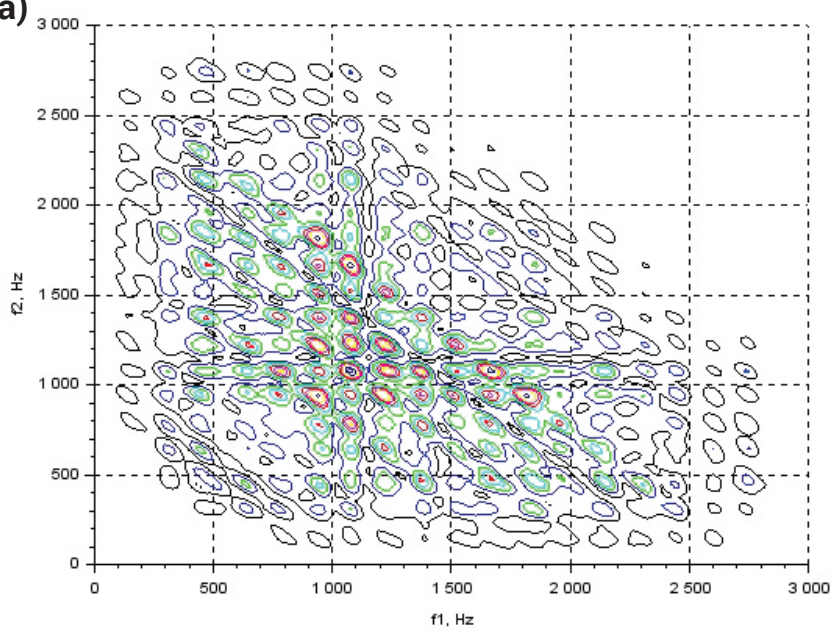

c)

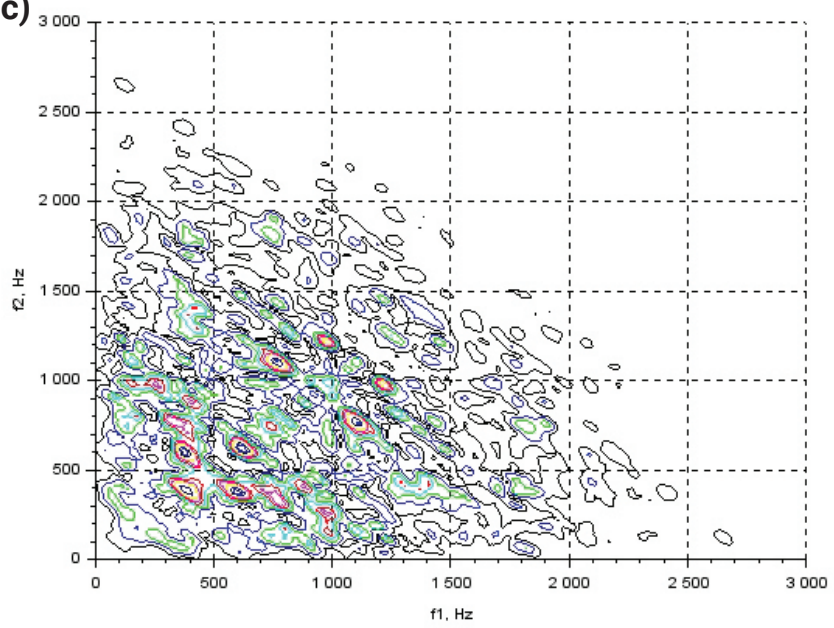

b)

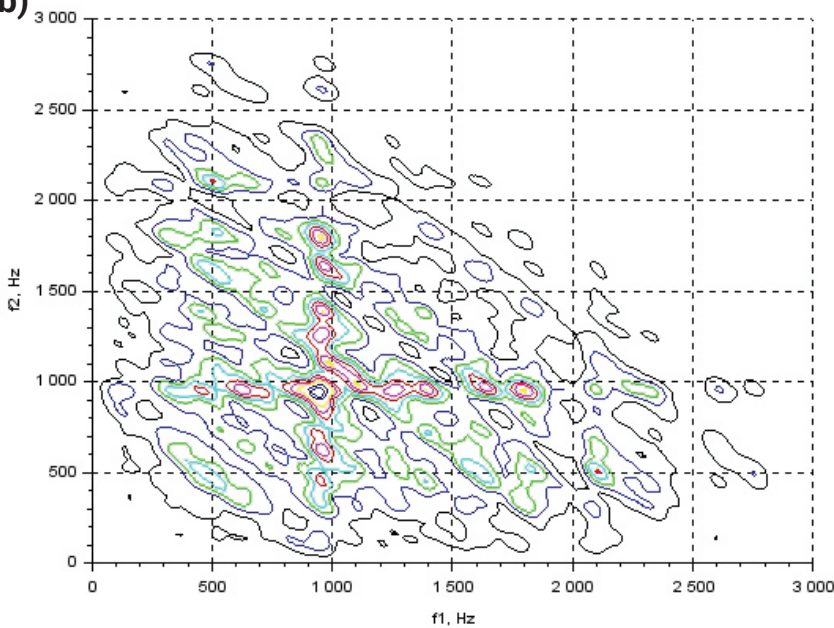

d)

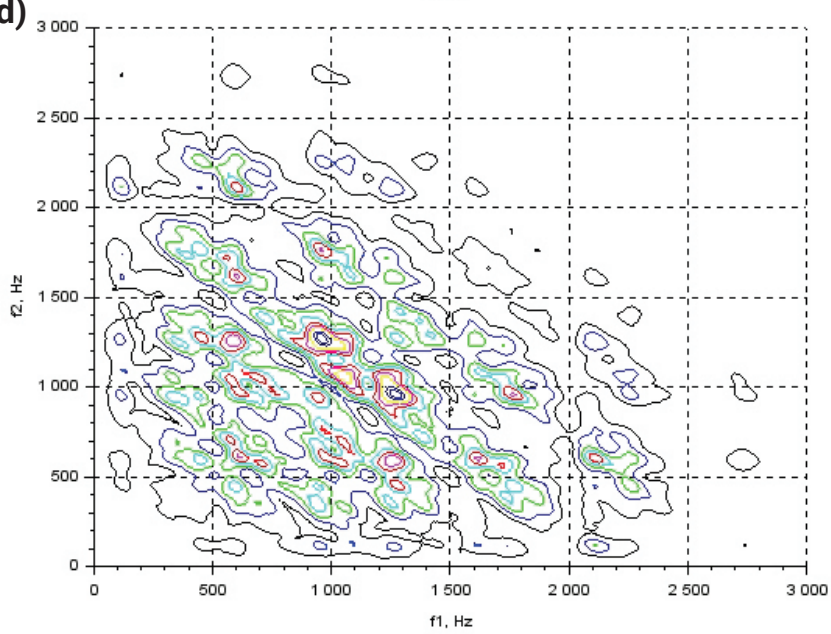

Rys. 5. Wykresy konturowe bispektrum wyznaczone dla sygnałów akustycznych spawania z: a) nieprawidłowym prądem spawania; b) nieprawidłowym napięciem spawania; c) brakiem gazu osłonowego; d) zabrudzeniami olejem

Fig. 5. Contour plots of bispectra of acoustic signal of welding process with: a) incorrect welding current; b) incorrect welding voltage; c) lack of shielding gas; d) oil contamination

Bazując na analizie bispektrów przeprowadzono ocenę możliwości detekcji niestabilności procesu spawania. Ze względu na dostępną ilość miejsca, w artykule przedstawiono wyniki analizy sygnału zarejestrowanego dla procesu spawania (stan S3), podczas którego symulowano zmiany napięcia. Na rysunku 6 zaprezentowano przebieg zarejestrowanego sygnału napięcia (pierwszy wykres od góry) oraz sygnału akustycznego (wykres środkowy). W sygnałach dostrzegalne są zmiany wartości amplitud w chwilach zmian napięcia przy czym łatwo dostrzec, że sygnał akustyczny dobrze odzwierciedla słabo widoczne zmiany napięcia spawania. Zgodnie z wcześniej przyjętą zasadą sygnał akustyczny całego procesu spawania podzielono na szereg krótkich podrealizacji o długości 0,2 s a następnie dla każdego fragmentu wyznaczono bispektrum na podstawie którego wyliczono parametr Sd zgodnie ze wzorem (8) (por. rozdz. 2). Taka operacja pozwoliła na wyznaczenie nowego sygnału parametrycznego, którego przebieg zaprezentowano na rysunku 6 (dolny wykres). Zastosowanie analizy bispektralnej $w$ tym przypadku pozwoliło na redukcję zakłóceń losowych występujących w sygnale akustycznym i wyraźne odzwierciedlenie zmian poziomu dźwięku wywołanych zmianami napięcia spawania.
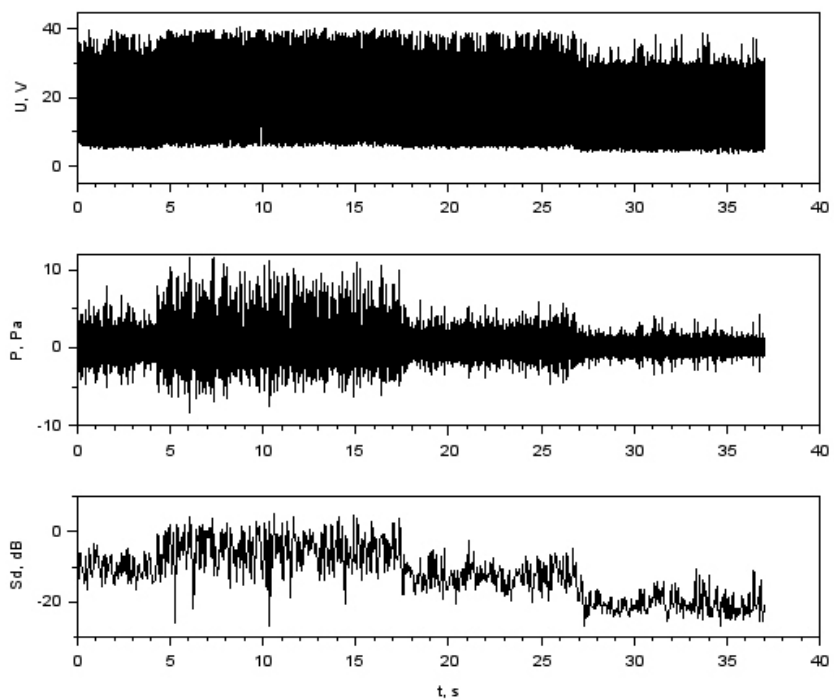

Rys. 6. Wykresy przedstawiające kolejno przebieg napięcia spawania, sygnał akustyczny i sygnał parametryczny wyznaczony na podstawie bispektów

Fig. 6. Plots of voltage signal of welding, acoustic signal and parametric signal calculated based on bispectra

\section{Podsumowanie}

Celem badań jest ocena możliwości zastosowania statystyk i widm wyższych rzędów do diagnozowania procesu spawania. Jak pokazują uzyskane wyniki analiza akustycznych sygnałów procesu spawania z zastosowaniem widm wyższych rzędów ma ogromny potencjał zarówno w kontekście opracowania nowych parametrów liczbowych opisujących składowe widma, jak rów- 
nież w zakresie detekcji i klasyfikacji różnych anomalii pojawiających się w trakcie spawania. Zaproponowanie parametru diagnostycznego Sd do tworzenia sygnałów parametrycznych pozwalających na detekcję niestabilności procesowych jest jednym z wielu możliwych rozwiązań. Generowanie sygnału parametrycznego wymaga określenia szerokości segmentów czasowych, dla których będzie wyznaczane widmo wyższego rzędu. Zastosowana w badaniach szerokość segmentu była efektem wstępnych badań. Zaobserwowano, że dla potrzeb detekcji różnych niestabilności procesu spawania konieczne jest zróżnicowanie szerokości segmentów, dla których wyznaczane są widma wyższych rzędów. Ponadto można stwierdzić, że na podstawie widm wyższych rzędów możliwe jest określenie zbioru cech relewantnych dopasowanych do rozpoznawania różnych niestabilności procesu spawania. Z punktu widzenia możliwości dalszych badań istotnym zagadnieniem będzie opracowanie odpowiednich metod przetwarzania i analizy sygnałów parametrycznych w celu podniesienia skuteczności detekcji nieprawidłowości procesowych.

\section{Literatura}

[1] Cudina M., Prezelj J., Polajnar I.: Use of audible sound for on-line monitoring of gas metal arc welding process, Metalurgija 47, 2008, pp. 81-85.

[2] Grad L., Kralj V.: On line monitoring of arc welding process using acoustic signals, In: Proc. 13th Conf. BIAM'96, Zagreb, 1996, pp. i17-i20.

[3] Grad L., Grum J., Polajnar I., Slabe J.M.: Feasibility study of acoustic signals for on-line monitoring in short circuit gas metal arc welding. Int. J. Mach. Tools Manuf. 44, 2004, pp. 555-561.

[4] Fan D., Shi Y., Ushio M.: Investigation of $\mathrm{CO}_{2}$ welding arc sound. Correlation of welding arc sound signal with welding spatter, Trans. JWRI 30, 2001, pp. 29-33.

[5] Jiluan P.: Arc Welding Control, Woodhead Publishing Ltd., 2003.

[6] Luksa K.: Correspondence between sound emissions generated in the GMA welding process and signals registered in the arc circuit, Weld. Int. 17,2003, pp. 438-441.

[7] Luo H., Zenga H., Hub L., Hub X., Zhoub Z.: Application of artificial neural network in laser welding defect diagnosis. J. Mater. Proc. Tech. 170, 2005, pp. 403-411.

[8] Mendel J.M.: Tutorial on higher-order statistics (spectra) in signal processing and system theory: Theoretical results and some applications, Proc. IEEE, Vol. 79, 1991, pp. 278-305.

[9] Nikias C.L., Petropulu A.P.: Higher-Order Spectra Analysis. Englewood Clifs NJ, Prentice-Hall, 1993. 